OPEN ACCESS

Edited by:

Luca Arcaini,

University of Pavia, Italy

Reviewed by:

Guido Gini,

Azienda Ospedaliero

Universitaria Ospedali Riuniti, Italy

*Correspondence:

Hongda Lu

phlonda@163.com

${ }^{\dagger}$ These authors have contributed equally to this work and share

first authorship

Specialty section: This article was submitted to Hematologic Malignancies, a section of the journal

Frontiers in Oncology

Received: 25 March 2021 Accepted: 16 June 2021

Published: 01 July 2021

Citation:

Cao $X$, Wang $Y$, Li P, Huang $W$, LuX and Lu H (2021) HBV

Reactivation During the Treatment of Non-Hodgkin Lymphoma and Management Strategies.

Front. Oncol. 11:685706. doi: 10.3389/fonc.2021.685706

\section{HBV Reactivation During the Treatment of Non-Hodgkin Lymphoma and Management Strategies}

\author{
Xing Cao ${ }^{1+}$, Yafei Wang ${ }^{2+}$, Panyun $\mathrm{Li}^{1}$, Wei Huang ${ }^{1}$, Xiaojuan $\mathrm{Lu}^{1}$ and Hongda $\mathrm{Lu}^{1 *}$ \\ ${ }^{1}$ Department of Oncology, The Central Hospital of Wuhan, Tongji Medical College, Huazhong University of Science and \\ Technology, Wuhan, China, ${ }^{2}$ Department of Respiratory and Critical Care Medicine, The Central Hospital of Wuhan, Tongji \\ Medical College, Huazhong University of Science and Technology, Wuhan, China
}

Hepatitis B virus reactivation (HBV-R), which can lead to HBV-related morbidity and mortality, is a common and well-known complication that occurs during the treatment of non-Hodgkin lymphoma (NHL) patients with current or past exposure to HBV infection. HBV-R is thought to be closely associated with chemotherapeutic or immunosuppressive therapies. However, immunosuppressive agents such as anti-CD20 antibodies (e.g., rituximab and ofatumumab), glucocorticoids, and hematopoietic stem cell transplantation (HSCT) administered to NHL patients during treatment can cause deep immunodepression and place them at high risk of HBV-R. In this review, we explore the current evidence, the guidelines of several national and international organizations, and the recommendations of expert panels relating to the definition, risk factors, screening and monitoring strategies, whether to use prophylaxis or pre-emptive therapy, and the optimal antiviral agent and duration of antiviral therapy for HBV-R.

Keywords: hepatitis B virus reactivation (HBV-R), risk factors, antiviral prophylaxis, non-Hodgkin lymphoma (NHL), rituximab, immunosuppressive therapy

\section{INTRODUCTION}

Hepatitis B virus (HBV) is a double-stranded DNA virus belonging to the family Hepadnaviridae (1). HBV infection has reached epidemic proportions globally. It is estimated that over one-third of the world's population has been infected with HBV, with approximately 248 million of them suffering from chronic infection $(2,3)$. Compared with uninfected individuals, those infected with HBV have a 2-3-fold greater risk of developing non-Hodgkin's lymphoma (NHL), particularly diffuse large B-cell lymphoma (DLBCL), which represents the major NHL subtype (4-9). Although the mechanism underlying this phenomenon remains unclear, it is likely to be due to the hepatotropic and lymphotropic nature of HBV, which can assure HBV replication in lymphoid tissue (10-12). Interestingly, it has been reported that HBV infection is uncorrelated with Hodgkin's lymphoma (HL) $(13,14)$. HBV reactivation (HBV-R) is defined as resolved/occult HBV that becomes active again, leading to adverse consequences. Occult $\mathrm{HBV}$ infection is characterized by the presence of replication-competent HBV DNA (i.e., covalently closed circular DNA [cccDNA] comprising the episomal HBV genome) in the liver and/or blood of hepatitis B surface antigen 
(HBsAg)-negative individuals as determined by currently available assays (15). Over recent years, a close link has been established between HBV-R and cytotoxic chemotherapeutic drugs, such as anthracyclines, cyclophosphamide, vincristine, and prednisone, as well as anti-CD20 monoclonal antibody therapy (e.g., rituximab) (16-21). Nevertheless, an RCHOP regimen comprising rituximab, anthracyclines, cyclophosphamide, vincristine, and prednisone is now widely used as the first-line treatment for NHL, highlighting the need to be vigilant for HBV-R in concerned patients. The rate of HBV-R in $\mathrm{HBsAg}(+)$ patients who undergo rituximab-containing therapy is reported to range from 33 to $65 \%$ and between 6 and $24 \%$ in those negative for $\mathrm{HBsAg}$ and positive for antihepatitis B core antibody ( $\mathrm{HBcAb})$, respectively (22). The clinical manifestations of HBV-R can vary from asymptomatic hepatitis to lethal liver failure (23). Additionally, patients with HBV-R may postpone scheduled chemotherapy or present with abnormal liver function, leading to adverse effects on treatment outcome for the primary disease $(24,25)$. There are no standard screening, monitoring, or management strategies for HBV-R, and recommendations for the clinical management of HBV-R for patients treated with R-CHOP differ among institutions. Here, we review the recent literature relating to HBV-R, as the appropriate and timely identification of $\mathrm{HBV}-\mathrm{R}$, as well as suitable strategies for its management, remain crucial for improving the quality of life of NHL patients.

\section{DEFINITION OF HBV-R}

No uniform criteria for the definition of HBV-R currently exist and different guidelines have heterogeneous definitions for HBV$\mathrm{R}$ diagnosis and management. The American Association for the Study of Liver Diseases (AASLD), the Asian Pacific Association for the Study of the Liver (APASL), and the American Gastroenterological Association (AGA) give clear definitions of HBV-R (26-28), whereas the European Association for the Study of the Liver (EASL) does not (29). Table 1 summarizes the definitions of HBV-R based on the different guidelines. Additionally, the AASLD also provides explicit concepts for $\mathrm{HBV}$-associated hepatitis, namely, acute serum alanine aminotransferase (ALT) levels $\geq 3$-fold higher than that at baseline and an absolute value $>100 \mathrm{U} / \mathrm{L}$ (26). Interestingly, it has been reported that monitoring ALT levels can lead to the earlier detection of HBV-R because ALT levels increase 2-3 weeks before a rise in HBV DNA levels is detected (31).

Collectively, HBV-R can be identified in a timely manner by combining ALT levels with HBV DNA and HBsAg. In HBsAg(+) patients, a dramatic rise in HBV DNA concentrations (usually 100 -fold or more) are indicative of $\mathrm{HBV}$ - $\mathrm{R}$, while in patients with resolved $\mathrm{HBV}$ infection (HBsAg[-] and $\mathrm{HBcAb}[+]$ ), $\mathrm{HBV}-\mathrm{R}$ usually means the reappearance of $\mathrm{HBsAg}$ or an increase in serum HBV DNA concentrations with or without $\mathrm{HBsAg}$ seroconversion and ALT exacerbation.

\section{RISK FACTORS AND POSSIBLE MECHANISM OF HBV-R DURING NHL TREATMENT}

Notably, HBV-R can be induced by coinfection with HBV and severe acute respiratory syndrome coronavirus 2 (SARS-CoV-2) (32-34). Other coinfections, such as that with HCV or HDV, can also increase the likelihood of HBV-R (35). The crucial risk factors for HBV-R can be classified into three types, namely, host-related, virus-related, and medication-related (35). Medication-related factors are usually associated with underlying disease that requires immunosuppressive therapy, such as chemotherapy, solid organ or bone marrow transplantation, rheumatological conditions, dermatological conditions, or inflammatory bowel disease) (36). As mentioned above, the drugs that are currently used to treat NHL (anthracyclines, cyclophosphamide, vincristine, prednisone, and anti-CD20 monoclonal antibody) are usually immunosuppressive, and constitute the focus of this review.

TABLE 1 | Definition of HBV-R according to different guidelines.

American Association for the Study of

Liver Diseases. (AASLD, 2018) (26)

The Asian Pacific Association for the Study of the Liver. (APASL, 2016) (27)
One of the following: 1) a $\geq 100$-fold elevation in the HBV DNA load compared with the baseline level; 2) $\geq 1,000 \mathrm{IU} / \mathrm{ml}$ of HBV DNA with an undetectable baseline level; 3) $\geq 10,000$ $\mathrm{IU} / \mathrm{ml} \mathrm{HBV}$ DNA if the baseline level is not available.

One of the following: 1) a $\geq 100$-fold increase in the HBV DNA load from baseline levels; 2) the reappearance of HBV DNA to a level of $100 \mathrm{IU} / \mathrm{ml}$ if the baseline level is undetectable; 3) $\geq 20,000 \mathrm{IU} / \mathrm{ml} \mathrm{HBV}$ DNA if the baseline level is not available.
One of the following: 1) HBV DNA is detectable; 2) reappearance of $\mathrm{HBsAg}$ One of the following:

1) reverse $\mathrm{HBsAg}$ seroconversion (reappearance of $\mathrm{HBsAg}$ ); 2) the appearance of HBV DNA in serum if $\mathrm{HBsAg}$ is negative A change in HBsAg status (negative to positive).

Not defined
One of the following:

1) de novo detectable HBV DNA if baseline level is undetectable; 2) a $\geq 10$-fold increase in HBV DNA levels if the baseline DNA level is detectable. Not defined
Not 


\section{Host-Related Risk Factors}

Males are more prone to undergoing HBV-R than females. Yeo et al. reported that in $600 \mathrm{HBsAg}(+)$ cancer patients exposed to chemotherapy, the HBV-R ratio was almost three-fold higher in men than women $(37,38)$. Additionally, people that are more than 50 years old, $\mathrm{HBeAg}(+)$, and with underlying disease that requires immunosuppressive therapy (e.g. lymphomas) are at greater risk of developing HBV-R (37).

\section{Virus-Related Risk Factors}

The virus-related, high-risk factors for HBV-R identified to date include detectable $\mathrm{HBV}$ DNA, $\mathrm{HBsAg}$ and $\mathrm{HBcAb}$ positivity, mutations in HBsAg, and HBV genotype $(23,39)$. Among these, detectable HBV DNA was reported to be the most important predictive factor for HBV-R. In one study, $37.8 \%$ of patients $(31 / 82)$ with detectable viral load developed HBV-R $(P=0.0003$, odds ratio [OR] 8.4, 95\% CI 2.6-27.2) (39). Salpini et al. further identified mutations in HBsAg as being risk factors for HBV-R. The authors analyzed HBsAg-associated genetic features and found that $75.9 \%$ of patients (22/29) with HBV-R carried HBsAg mutations compared with $3.1 \%$ for control patients $(2 / 64 ; P<0.001)$. Among the HBsAg mutations identified, $61.5 \%$ were found to reside in a major hydrophilic region, while some were known immune escape-associated mutations, such as the sD144E mutation that disrupts humoral response-mediated HBsAg recognition. The remaining mutations were found to reside in class-I/II-restricted Tcell epitopes, suggesting that they were important for HBV escape from T-cell-mediated responses (40). $\mathrm{HBsAg}(+)$ patients have an eight-fold higher likelihood of HBV-R when compared with patients with resolved infection (HBsAg[-] and $\mathrm{HBcAb}[+])$ (41). Notably, HBV genotype A is rarely involved in HBV-R, while other genotypes are reported $(35,42)$. Coinfection with other viruses, such as HCV, HDV, HIV, or SARS-CoV-2, also puts patients at higher risk of $\mathrm{HBV}-\mathrm{R}$, as mentioned before $(26,35)$.

\section{Medication-Related Risk Factors}

Numerous studies have indicated that immunosuppressive and chemotherapeutic medications represent the major risk for
HBV-R (43-45). The greatest and most reported risk for HBV-R is associated with B-cell-depleting therapy, such as that with the antiCD20 antibody, rituximab (35). The AGA and the AASLD have stratified the HBV-R-related risk of individual medications or therapies $(26,30)$. Additionally, the risk of HBV-R has been graded through different immunosuppressive treatments and HBV infection status, as follows (Table 2): (1) Very high risk, greater than $20 \%$ chance of reactivation, and is associated with anti-CD20 antibody therapy (rituximab or ofatumumab) and hematopoietic stem cell transplantation (HSCT); (2) high risk, between 10 and $20 \%$ chance of reactivation, and is mainly related to high-dose glucocorticoid and anthracycline treatment; (3) moderate risk, between 1 and $10 \%$ chance of reactivation; (4) low risk, less than $1 \%$ chance of reactivation (30, 35, 45-47). Importantly, the immunosuppressive therapies included in the very-high- and high-risk groups are those usually administered to NHL patients, rendering them prone to HBV-R and incidental adverse events.

\section{Anti-CD20 Antibodies-Rituximab and Ofatumumab}

Rituximab, approved in 1997, is used for the treatment of NHL and chronic lymphocytic leukemia. Numerous cases of $\mathrm{HBsAg}(+)$ lymphoma patients treated with rituximab-containing therapy developing HBV-R have been documented since 1999 (48, 49). Rituximab and ofatumumab are humanized anti-CD20 monoclonal antibodies targeting CD20, a cell-surface marker on B lymphocytes, resulting in B-cell depletion and the subsequent impairment of Bcell antigen-presenting function, with the consequent reduction of specific anti-HBV CD4-positive T-cell activation and proliferation (50). Rituximab affects cell signaling by directly inducing the apoptosis of malignant B cells and activating complementdependent cytotoxicity. These effects result in the rapid death of rituximab-targeted cells and the activation of natural killer (NK) cells, which then produce interferon-gamma (IFN $\gamma$ ), and thereby induce antibody-dependent cellular cytotoxicity when they interact with rituximab-coated target cells (51).

Ofatumumab functions through a similar mechanism. These types of drugs are commonly associated with serious HBV-R-

TABLE 2 | HBV-R risk groups based on patient infection status and associated immunosuppressive treatment.

\begin{tabular}{|c|c|c|c|}
\hline Risk group & HBV-R rate (\%) & Hepatitis status & Associated medications \\
\hline Very high risk & $>20 \%$ & Chronic infection & Anti-CD20 monoclonal antibodies (rituximab, ofatumumab), HSCT \\
\hline High risk & $10-20 \%$ & Chronic infection & $\begin{array}{l}\text { Anthracycline derivatives: daunorubicin, doxorubicin, epirubicin } \\
\text { High-dose glucocorticoids (>20 mg/day for } 4 \text { weeks and longer) } \\
\text { Anti-CD52 antibody: alemtuzumab }\end{array}$ \\
\hline Moderate risk & $1-10 \%$ & Chronic infection & $\begin{array}{l}\text { Cytotoxic therapy without glucocorticoids: } \\
\text { cyclophosphamide, vincristine; } \\
\text { TNF- } \alpha \text { inhibitors: infliximab, etanercept, golimumab, adalimumab; } \\
\text { Cytokine and integrin inhibitors (mogamulizumab); } \\
\text { Tyrosine kinase inhibitors (TKIs): imatinib, dasatinib, nilotinib; } \\
\text { Proteasome inhibitors: carfilzomib }\end{array}$ \\
\hline Low risk & $<1 \%$ & $\begin{array}{l}\text { Chronic infection } \\
\text { Resolved infection }\end{array}$ & $\begin{array}{l}\text { Glucocorticoids (methotrexate or azathioprine) lasting less than a } \\
\text { week or a low-dose (<10 mg prednisone) within } 4 \text { weeks } \\
\text { High-dose glucocorticoid or the anti-CD52 antibody alemtuzumab }\end{array}$ \\
\hline
\end{tabular}

HBsAg, hepatitis B surface antigen; HBCAb, anti-hepatitis B core antibody; HSCT, hematopoietic stem cell transplantation; TNF, tumor necrosis factor.

Chronic infection: $\mathrm{HBSAg}(+)$ and $\mathrm{HBCAb}(+)$ patients.

Resolved infection: $\mathrm{HBSAg}(-)$ and $\mathrm{HBCAb(+)}$ patients. 
related events and can increase the risk of hepatocyte dysfunction and mortality if $\mathrm{HBV}-\mathrm{R}$ is not quickly identified and cleared $(35,52)$. Few retrospective data are available for the incidence of $\mathrm{HBV}-\mathrm{R}$ in $\mathrm{HBs} \mathrm{Ag}(+)$ patients treated with rituximab-containing therapy without any antiviral prophylaxis. The HBV-R rate in NHL patients has been reported to vary between 18.2 and $80 \%$. HBV-R occurs from after a few weeks to up to 55 months after rituximab administration, indicating that rituximab represents a very high-risk factor for HBV-R (48, 53-57). Between 1997 and 2009, the US Food and Drug Administration (FDA) MedWatch Database reported 118 cases of HBV-R. Among these patients, those administered rituximab-containing therapy had a prominently increased risk of HBV-R compared with those given non-rituximab-containing therapy (OR 5.73, 95\% CI 2.01-16.33, $P=0.0009$ ) without heterogeneity (19). Consequently, the FDA alerted healthcare professionals that rituximab and ofatumumab were associated with a high risk of HBV-R and added "boxed warnings" (the strongest warnings) to the product labels in September 2013 (58). In the Emerging Trends Conference sponsored by the AASLD held in 2015, entitled "Reactivation of Hepatitis B," HBV-R was reported to be a possible underestimated clinical challenge related to ofatumumab or rituximab treatment. Furthermore, it was suggested that all patients undergoing ofatumumab- or rituximab-containing therapies should be screened for HBV-R, and that $\mathrm{HBsAg}(+)$ or $\mathrm{HBcAb}(+)$ patients should start prophylactic antiviral therapy to prevent HBV-R (59).

Collectively, these data indicate that rituximab and other Bcell-depleting therapies pose the greatest risk for $\operatorname{HBV}-\mathrm{R}(35,46$, $60)$, which warrants vigilance by the medical community.

\section{Corticosteroids}

Corticosteroids were first reported to be associated with HBV-R by Sagnelli et al. in 1980, which was subsequently widely confirmed $(38,61)$. The risk for HBV-R with corticosteroid use is deemed to be dose- and time-dependent, with studies having indicated that a high dose ( $>20 \mathrm{mg} /$ day) of chronic prednisone therapy for longer than 4 weeks is associated with a high risk of HBV-R $(28,62)$. Cheng et al. conducted a randomized study on $50 \mathrm{HBsAg}(+)$ lymphoma patients and compared the HBV-R rate in patients undergoing an identical chemotherapeutic regimen receiving or not corticosteroid treatment. The authors reported that the cumulative incidence of $\mathrm{HBV}-\mathrm{R}$ at 9 months was significantly higher in the corticosteroid treatment group (38 vs. $73 \%, P=0.03$ ) (63). In a recent 6-year prospective cohort study, HBV-R was reported to occur a median of 10 months (range, 4-32) after steroid administration (53).

Corticosteroids enhance HBV replication mainly through two mechanisms. First, they suppress cell-mediated immunity via the inhibition of interleukins, which then prevents $\mathrm{T}$ and $\mathrm{B}$ cell proliferation (43). Second, corticosteroids stimulate the glucocorticoid-responsive element present in the HBV genome, thereby exerting a direct suppressive effect on T-cell-mediated immunity $(23,64)$. Corticosteroids were also reported to be able to increase HBsAg secretion via inducing autophagy, i.e., inhibiting autophagy using 3-MA, an autophagy inhibitor, decreased HBV replication and HBsAg secretion (65); however, this possibility requires further investigation. These observations suggest that the reported HBV-R in patients coinfected with SARS-CoV-2 and HBV might be associated with corticosteroid use during the treatment of COVID-19. The R-CHOP regimen, which contains prednisone, is still conventionally administered to patients with NHL as first-line standard therapy. Hence, the risk for HBV-R should be taken into consideration when treating NHL patients with a corticosteroid-containing regimen.

\section{Anthracyclines}

Anthracyclines, such as doxorubicin and epirubicin, have also been linked to a high risk of $\operatorname{HBV}-\mathrm{R}(35,66)$. This class of chemotherapeutic drugs is applied to treat a variety of solid and hematological cancers, including lymphoma, bladder cancer, softtissue sarcoma, leukemia, breast cancer, and multiple myeloma. Doxorubicin exerts its HBV-R-related effects by increasing the expression of the cell cycle regulator p21 (Waf1/Cip1), which upregulates the expression level of enhancer-binding protein $\alpha$ $(\mathrm{C} / \mathrm{EBP} \alpha)$ and, consequently, promotes the binding of $\mathrm{C} / \mathrm{EBP} \alpha$ to the HBV promoter; this, in turn, enhances HBV transcription, and thus also viral replication (67). Nevertheless, it is difficult to evaluate the anthracycline-associated risks for $\mathrm{HBV}-\mathrm{R}$ as these drugs are often used in combination with other immunosuppressive or chemotherapeutic agents, such as rituximab.

\section{Immune Checkpoint Inhibitors}

Immune checkpoint inhibitors (ICPIs), such as antibodies targeting programmed cell death protein 1/programmed cell death 1 ligand 1 (PD-1/PD- L1) (anti-PD-1: pembrolizumab and nivolumab; anti-PD-L1: atezolizumab, durvalumab, and avelumab) and cytotoxic T-lymphocyte-associated protein 4 (anti-CTLA4: ipilimumab and tremelimumab), have been used as immunotherapy in the treatment of various types of cancer. Pembrolizumab is an FDA-approved agent used to treat relapsed or refractory primary mediastinal large B-cell lymphoma after $\geq 2$ prior lines of therapy. It has been suggested that this class of drugs may give rise to HBV-R. Given that their mechanism of action involves activating the immune system, it seems unlikely that ICPIs induce HBV-R (35); however, sporadic incidents of HBV-R after ICPI administration have been described in case reports and a retrospective cohort study (68-72). In the latter, of $114 \mathrm{HBsAg}(+)$ patients given anti-PD-1/PD-L1 antibody therapy, six $(5.3 \%)$ developed HBV-R in a median time of 18 weeks after treatment initiation (72). Therefore, given the concern that ICPI treatment may lead to HBV-R, prophylactic antiviral therapy should be an appropriate option for $\mathrm{HBV}$ infected or resolved patients undergoing ICPI therapy.

Other biological agents, such as TNF- $\alpha$ inhibitors (infliximab, etanercept, golimumab, and adalimumab), tyrosine kinase inhibitors (TKIs: imatinib, dasatinib, and nilotinib), the Janus kinase (JAK) 1/2 inhibitor ruxolitinib, and the proteasome inhibitor bortezomib, are also thought to be related to HBV-R; however, they are not currently applied to lymphomas $(38,44)$. 


\section{SCREENING BEFORE TREATMENT}

The prevention of HBV-R begins with patient screening. Numerous approaches have been adopted by different organizations and institutions to address the issue of screening for HBV infection before the initiation of immunosuppressive therapy. There is a consensus among various cancer governing bodies that all patients at high risk of HBV-R or those receiving B-cell-depleting therapies should be screened before the initiation of therapy $(26,30,35)$. The AGA, AASLD, EASL, and the American Society of Clinical Oncology (ASCO) screening guidelines are presented in Table $\mathbf{3}(26,28,29,73)$. The National Comprehensive Cancer Network (NCCN) Guidelines for B-cell lymphomas suggest that both HBsAg and $\mathrm{HBcAb}$ should be tested among NHL patients before the beginning of immunosuppressive treatment, especially that involving anti-CD20 antibody-containing regimens. The baseline HBV DNA burden should be obtained if patients are positive for $\mathrm{HBsAg}$ or $\mathrm{HBcAb}$ to quickly detect $\mathrm{HBV}-\mathrm{R}$ and take the appropriate measures (74).

Owing to the immunosuppressive agents used in the treatment of NHL that place patients at a very high, high, or moderate risk of HBV-R, all NHL patients should be tested for $\mathrm{HBV}$ infection (at least for HBsAg and HBcAb) before the initiation of therapy to minimize the risk of $\mathrm{HBV}-\mathrm{R}$ and related complications, including mortality.

\section{MANAGEMENT STRATEGIES FOR HBV-R IN CLINICAL PRACTICE}

After screening, the next challenge is the management of HBV-R in individuals receiving immunosuppressive agents. There are two strategies targeting $\mathrm{HBV}-\mathrm{R}$, namely, antiviral prophylaxis and pre-emptive therapy. Antiviral prophylaxis means treating patients (usually at least 1 week before immunosuppressive therapy) with $\mathrm{HBs} \mathrm{Ag}(+)$ or $\mathrm{HBcAb}(+)$ regardless of viral load or whether or not there are clinical symptoms of HBV-R. Preemptive therapy refers to the close surveillance of HBV DNA, in which antiviral therapy begins at the first sign of an increase in the HBV DNA load $(26,74,75)$. The guidelines for management strategies are also presented in Table 3.

In oncological practice, it is usually too late to take measures to deal with HBV-R and schedule treatments are interrupted when HBV-R begins to take shape causing poor outcomes for NHL patients. Consequently, we think that it is appropriate to initiate antiviral prophylaxis before immunosuppressive therapies are given to NHL patients.

\section{Agents for Antiviral Prophylaxis}

To date, no antiviral medication has been approved for the prevention of HBV-R. Two types of treatment are available for patients with chronic $\mathrm{HBV}$ infection, including nucleoside analogs (NAs) and interferon-alpha. However, interferons are no longer conventionally used to treat lymphoma patients owing to the associated intolerance, adverse effects, and selective effectiveness (46). Hence, several NAs, such as entecavir (ETV), lamivudine (LMV), adefovir, and tenofovir, are the only effective options available for the treatment of HBV-R among NHL patients.

\section{Lamivudine}

LMV is a cost-effective alternative for HBV treatment and was the first NA approved for this purpose. Consequently, it has been widely used for antiviral prophylaxis among NHL patients (76). In the first study, none of $30 \mathrm{HBsAg}(+)$ patients with lymphoma undergoing intensive chemotherapy experienced HBV-R in the LMV prophylaxis group, whereas 8 out of 15 patients $(53 \%)$ in the no-prophylaxis arm had HBV-R $(P=0.002)$. Survival free from HBV-R-related hepatitis in the group receiving LMV prophylaxis was significantly longer than that of the control group ( $P=0.002$ on the log-rank test) (77). In the second randomized trial, among 51 patients undergoing $\mathrm{CHOP}$ chemotherapy, HBV-R was detected in $30.8 \%$ (95\% CI, $14.3-$ $51.8 \%)$ of those undergoing LMV prophylaxis vs. 60\% (95\% CI, $38.7-78.9 \%)$ for those not receiving LMV treatment $(P=0.05)$ (78). A meta-analysis involving 16 studies reported that the $\mathrm{HBV}-\mathrm{R}$ rate was significantly lower in patients receiving LMV prophylaxis than in those of the control group (8.6\% [11/127] vs. $50.6 \%$ [136/269], respectively), suggesting that LMV can reduce the incidence of HBV-R (relative risk [RR] 0.21, 95\% CI $0.13-$ 0.35 ), as well as HBV-related mortality (RR 0.68 , 95\% CI 0.19 2.49) (79). A recent retrospective study (80) on consecutively enrolled $\mathrm{HBsAg}(-)$ and $\mathrm{HBcAb}(+)$ NHL patients who received rituximab-based chemotherapy found that none of the patients who were given LMV prophylaxis experienced HBV-R or treatment-related side effects (81). However, the long-term use of LMV is liable to generate a high rate of drug resistance, especially when used beyond 1 year. The incidence of resistance to LMV has been reported to be as high as $20 \%$ in patients treated for more than 1 year with non-immunosuppressive-containing medication (30); this incidence escalated dramatically to $30 \%$ after 2 years, and then increased exponentially with continued use (76). The most commonly identified mutation conferring resistance to LMV occurs in the tyrosine-methionine-aspartateaspartate (YMDD) motif of the HBV-DNA polymerase gene (82). Hence, owing to the low threshold for the generation of resistance to LMV (83), this drug was replaced by nextgeneration NAs such as ETV or tenofovir that possess a high barrier to resistance, as demonstrated by multiple studies and meta-analyses $(28,80,84,85)$.

\section{Entecavir and Tenofovir}

ETV and tenofovir disoproxil fumarate are new-generation NAs that have a high barrier to drug resistance and superior viral suppressive capability $(23,86-88)$. A retrospective analysis of HBsAg(+) NHL patients (stage III-IV) who received antiviral prophylaxis with ETV $(n=34)$ or $\operatorname{LMV}(n=89)$ during chemotherapy suggested that ETV-treated patients had lower rates of hepatitis (5.9 vs. 27.0\%, $P=0.007)$ and HBV-R (0 vs. $12.4 \%, P=0.024)$, as well as fewer interruptions of chemotherapy (5.9 vs. $20.2 \%, P=0.042$ ) (89) compared with those treated with LMV. A prospective, randomized, multicenter clinical trial 


\section{Guidelines \\ Screen \\ Management strategies for HBV-R}

object

Duration of antiviral therapy

Monitoring during

prophylaxis

Monitoring after prophylaxis

American Association for the

Study of Liver Diseases (AASLD,

2018) (26)

The Asian Pacific Association for All patients

the Study of the Liver (APASL,

2016) (27)

American Gastroenterologica Association (AGA, 2015) (30)

Patients at

Chronic infection: prophylaxis At least 6 months (12 months for

therapy, but prophylaxis is needed when patients are receiving anti-CD20 antibody therapy

At least 6 months $(12$ months for

Not mentioned

HBV DNA levels should

immunosuppressive therapy

(B. cancer patients: prophylaxis;

therapy) after the completion of

Resolved HBV with

At least 12 months after the cessation

of therapy

detectable HBV DNA: prophylaxis:

Resolved HBV with

undetectable HBV DNA: pre-emptive therapy, excep

with anti-CD20 antibody therapy or stem cell

transplantation

moderate or Low risk: routine prophylaxis not recommended

high risk of

HBV-R

European Association for

the Study of the Live

(EASL, 2017) (29)

American Society of Clinical

All patients

$\mathrm{HBsAg}(+)$ patients: prophylaxis;

Resolved HBV, high risk: prophylaxis:

Resolved HBV, moderate and low risk: pre-emptive

therapy (monitor HBsAg and HBV DNA every 1-3

months)

All cancer $\quad \mathrm{HBsAg}(+)$ patients: prophylaxis;

Oncology (ASCO, 2020) (73)

patients

Resolved HBV, high risk: prophylaxis;

Resolved HBV, moderate

and low risk: pre-emptive therapy (monitor HBsAg

and HBV DNA every 3 months) following anticancer therapy

The same as for AASLD

At least 12 months after the cessation of immunosuppressive treatment and at

least 18 months for rituximab-based

regimens

levels should be tested

every 6 months during

antiviral therapy

No recommendation be tested every 1-3 months

Not mentioned

undetectable HBV DNA:

ALT and HBV DNA

every

1-3 months

No recommendation

function tests and HBV DNA should be tested every 3-6 months

$\mathrm{HBsAg}(+)$ and resolved HBV with high risk: at least monthly for the first 3 month after the cessation of antiviral therapy and every 3 months

thereafter

HBsAg, hepatitis B surface antigen; ALT, alanine aminotransferase. 
conducted in China that included 121 patients compared the efficacy of ETV $(n=61)$ and LMV $(n=60)$ in preventing HBV-R among $\mathrm{HBsAg}(+)$ patients undergoing $\mathrm{R}-\mathrm{CHOP}$ treatment for DLBCL. The results indicated that patients in the ETV group had a markedly lower incidence of HBV-related hepatitis (0 vs. $13.3 \%, P=0.003)$ and HBV-R (6.6 vs. $30 \%, P=0.001)$, as well as fewer interruptions of chemotherapy (1.6 vs. $18.3 \%, P=$ 0.002 ), with respect to those in the LMV group. No difference in terms of incidence of adverse events was identified between these two agents (90). Another meta-analysis that included 770 lymphoma patients also confirmed that patients with $\mathrm{HBsAg}(+)$ receiving LMV prophylaxis during chemotherapy had a significantly higher chance of $\mathrm{HBV}-\mathrm{R}$ compared with those receiving ETV (OR 5.0, $P<0.001$ ) (80). In a study conducted to evaluate the effectiveness of tenofovir for the treatment of HBV-R in patients undergoing immunosuppressive treatment, 25 of 38 patients were given tenofovir as prophylaxis, and 13 were administered the drug as pre-emptive therapy. None of the patients receiving tenofovir as prophylaxis developed HBV-R during immunosuppression. In addition, the remaining 13 patients received tenofovir at the first sign of $\mathrm{HBV}-\mathrm{R}$ and all had a complete biochemical and virological response within 9 months (91).

Based on the above observations, ETV or tenofovir (especially ETV) is recommended as the standard agent for the prevention and treatment of HBV-R by NCCN, AASLD, and others as they possess superior viral suppressive ability and a high barrier to resistance $(26,35,74,92)$.

\section{Duration of Therapy and Monitoring}

The optimal duration of prophylactic antiviral therapy remains controversial. Data derived from multiple sources indicate that antiviral prophylaxis should last for at least 6 months after the cessation of immunosuppressive therapy, and should be lengthened to 12 months for patients receiving regimens with B-cell-depleting therapies or antiviral prophylaxis $(46,86)$. The reason for extending the duration of antiviral prophylaxis use is that immune recovery may take longer, while the immunosuppressive effects of rituximab have been reported to persist for longer than 1 year after the last delivery $(35,93)$. HBV$\mathrm{R}$ has also been reported to occur more than 2 years after the completion of rituximab-containing chemotherapy (54, 94). The AGA, AASLD, EASL, and ASCO guidelines regarding the duration of therapy and monitoring are presented in Table 3. Additionally, the NCCN guidelines for B-cell lymphomas recommend that monitoring and antiviral prophylaxis should be continued for at least 12 months after the completion of anticancer treatment, and that HBV DNA levels should be tested monthly during treatment, and then every 3 months after completion of antiviral prophylaxis (74).

In the clinic, prophylactic antiviral therapy tends to be delivered before or at the onset of anticancer therapy to patients with prior $\mathrm{HBV}$ infection, regardless of baseline HBV DNA levels, because HBV-R has been reported to occur even after 1 year of infection. Consequently, close monitoring and longer use of antiviral prophylaxis should be considered, particularly in patients receiving anti-CD20-antibodycontaining therapy $(84,95-97)$.

\section{DISCUSSION}

HBV-R in NHL patients undergoing immunosuppressive therapies, especially rituximab-containing treatment, is now a well-recognized and preventable complication in clinical practice. Nevertheless, there is a large knowledge gap in our understanding of this disease process, making HBV-R a vexing and persistent problem. Among NHL patients with chronic HBV infection, HBV-R has gained extensive attention because of the associated significant morbidity and mortality. The immunosuppressive therapies used during the entire NHL treatment period, such as anti-CD20 antibody therapy, glucocorticoid treatment, and HSCT, usually amplify the odds of $\mathrm{HBV}-\mathrm{R}$, as mentioned before. Whether to screen patients at risk, stratify patients for risk based on $\mathrm{HBV}$ serological status and type of immunosuppression, whether to use prophylaxis or preemptive therapy, and the identification of the optimal antiviral agent and treatment duration remain unresolved issues.

Several screening strategies have been proposed by different organizations, namely, risk factor-based, risk-adaptive, and universal screening. HBV testing rates in cancer patients before therapy based on risk factors have been estimated to be low (1955\%) (98-100); however, the morbidity associated with HBV risk factors among patients with cancer may be high (101). Universal screening is the preferred option for the AGA and the AASLD given the limitations of risk factor-based and risk-adaptive screening. These two organizations recommend universal HBV screening as a reasonable and cost-effective strategy before anticancer therapies are administered to reduce the risk of HBV-R $(26,30)$. Accordingly, it is appropriate to test HBsAg, $\mathrm{HBcAb}$, and HBsAb (if available) among all NHL patients to identify and cure HBV-R earlier and provide better clinical outcomes.

The current guidelines agree that $\mathrm{HBsAg}(+)$ patients or those receiving anti-CD20 antibody therapy or HSCT are at high risk of HBV-R and should be given prophylaxis until after the cessation of anticancer therapy. Among moderate or low-risk HBV-R patients, pre-emptive antiviral therapy initiating at the first sign of HBV-R may also be a decent option. Recent studies and multiple meta-analysis have demonstrated the greater efficacy and lesser drug resistance of ETV and tenofovir as first-line agents for the prevention of HBV-R. The optimal duration of prophylaxis for HBV-R remains unclear. Indeed, Tasuku et al. reported a rare case of a 54-year-old woman diagnosed with DLBCL and $\mathrm{HBsAg}(-)$ and $\mathrm{HBcAb}(+)$ in whom HBV-R occurred 55 months after the completion of chemotherapy (54). Owing to the deep immunodepression exerted by rituximab or HSCT, lifelong antiviral treatment may be the better option $(23,102)$.

In the era of immunotherapy, numerous novel agents have emerged targeting the treatment of NHL and other solid cancers; however, prospective data showing how they interact with the 
immune system and their relation to $\mathrm{HBV}-\mathrm{R}$ are limited. Additional, well-designed, prospective studies are needed to allow the stratification of patients at risk of HBV-R as well as a better understanding of the appropriate antiviral therapy and the optimal duration of prophylaxis. With accumulating evidence and experience, it is expected that HBV-R can be avoided, identified, controlled, and, perhaps cured.

\section{REFERENCES}

1. Suhail M, Abdel-Hafiz H, Ali A, Fatima K, Damanhouri GA, Azhar E, et al. Potential Mechanisms of Hepatitis B Virus Induced Liver Injury. World J Gastroenterol (2014) 20(35):12462-72. doi: 10.3748/wjg.v20.i35.12462

2. Lee WM. Hepatitis B Virus Infection. N Engl J Med (1997) 337(24):1733-45. doi: 10.1056/NEJM199712113372406

3. Schweitzer A, Horn J, Mikolajczyk RT, Krause G, Ott JJ. Estimations of Worldwide Prevalence of Chronic Hepatitis B Virus Infection: A Systematic Review of Data Published Between 1965 and 2013. Lancet (2015) 386 (10003):1546-55. doi: 10.1016/S0140-6736(15)61412-X

4. Kang X, Bai L, Han C, Qi X. . doi: 10.2147/cmar.s244381

5. Qi Z, Wang H, Gao G. Association of Risk of non-Hodgkin's Lymphoma With Hepatitis B Virus Infection: A Meta-Analysis. Int J Clin Exp Med (2015) 8(12):22167-74.

6. Su TH, Liu CJ, Tseng TC, Chou SW, Liu CH, Yang HC, et al. Chronic Hepatitis B is Associated With an Increased Risk of B-cell non-Hodgkin's Lymphoma and Multiple Myeloma. Aliment Pharmacol Ther (2019) 49 (5):589-98. doi: 10.1111/apt.15132

7. Zhou X, Wuchter P, Egerer G, Kriegsmann M, Mataityte A, Koelsche C, et al. Role of Virological Serum Markers in Patients With Both Hepatitis B Virus Infection and Diffuse Large B-cell Lymphoma. Eur J Haematol (2019) 103(4):410-6. doi: 10.1111/ejh.13300

8. Zhou X, Pan H, Yang P, Ye P, Cao H, Zhou H. Both Chronic HBV Infection and Naturally Acquired HBV Immunity Confer Increased Risks of B-cell non-Hodgkin Lymphoma. BMC Cancer (2019) 19(1):477. doi: 10.1186/ s12885-019-5718-x

9. Taborelli M, Polesel J, Montella M, Libra M, Tedeschi R, Battiston M, et al. Hepatitis B and C Viruses and Risk of Non-Hodgkin Lymphoma: A CaseControl Study in Italy. Infect Agent Cancer (2016) 11:27. doi: 10.1186/ s13027-016-0073-x

10. Chen J, Wang J, Yang J, Zhang W, Song X, Chen L. Concurrent Infection of Hepatitis B Virus Negatively Affects the Clinical Outcome and Prognosis of Patients With non-Hodgkin's Lymphoma After Chemotherapy. PLoS One (2013) 8(7):e69400. doi: 10.1371/journal.pone.0069400

11. Coluccio C, Begini P, Marzano A, Pellicelli A, Imperatrice B, Anania G, et al. Hepatitis B in Patients With Hematological Diseases: An Update. World J Hepatol (2017) 9(25):1043-53. doi: 10.4254/wjh.v9.i25.1043

12. Kwok RM, Tran TT. Hepatitis B and Risk of Non-Hepatocellular Carcinoma Malignancy. Clin Liver Dis (2016) 20(4):693-702. doi: 10.1016/j.cld.2016.06.005

13. Marcucci F, Mele A. Hepatitis Viruses and non-Hodgkin Lymphoma: Epidemiology, Mechanisms of Tumorigenesis, and Therapeutic Opportunities. Blood (2011) 117(6):1792-8. doi: 10.1182/blood-2010-06-275818

14. Marcucci F, Spada E, Mele A, Caserta CA, Pulsoni A. The Association of Hepatitis B Virus Infection With B-Cell Non-Hodgkin Lymphoma - a Review. Am J Blood Res (2012) 2(1):18-28.

15. Raimondo G, Locarnini S, Pollicino T, Levrero M, Zoulim F, Lok AS, et al. Update of the Statements on Biology and Clinical Impact of Occult Hepatitis B Virus Infection. J Hepatol (2019) 71(2):397-408. doi: 10.1016/j.jhep.2019.03.034

16. Kim HY, Kim W. Chemotherapy-Related Reactivation of Hepatitis B Infection: Updates in 2013. World J Gastroenterol (2014) 20(40):14581-8. doi: 10.3748/wjg.v20.i40.14581

17. Kusumoto S, Arcaini L, Hong X, Jin J, Kim WS, Kwong YL, et al. Risk of HBV Reactivation in Patients With B-Cell Lymphomas Receiving Obinutuzumab or Rituximab Immunochemotherapy. Blood (2019) 133 (2):137-46. doi: 10.1182/blood-2018-04-848044

18. Hwang JP, Barbo AG, Perrillo RP. Hepatitis B Reactivation During Cancer Chemotherapy: An International Survey of the Membership of the American

\section{AUTHOR CONTRIBUTIONS}

HL conceived and designed the study and reviewed the manuscript. XC and YW collected the data and wrote the manuscript. PL, WH, and XL revised the manuscript. XC designed and wrote the table. All authors contributed to the article and approved the submitted version.

Association for the Study of Liver Diseases. J Viral Hepat (2015) 22(3):34652. doi: 10.1111/jvh.12305

19. Evens AM, Jovanovic BD, Su YC, Raisch DW, Ganger D, Belknap SM, et al. Rituximab-Associated Hepatitis B Virus (HBV) Reactivation in Lymphoproliferative Diseases: Meta-Analysis and Examination of FDA Safety Reports. Ann Oncol (2011) 22(5):1170-80. doi: 10.1093/annonc/mdq583

20. Yeo W, Chan TC, Leung NW, Lam WY, Mo FK, Chu MT, et al. Hepatitis B Virus Reactivation in Lymphoma Patients With Prior Resolved Hepatitis B Undergoing Anticancer Therapy With or Without Rituximab. J Clin Oncol (2009) 27(4):605-11. doi: 10.1200/JCO.2008.18.0182

21. Castelli R, Ferraris L, Pantaleo G, Lambertenghi Deliliers G, Cicardi M. High Rate of Hepatitis B Viral Breakthrough in Elderly Non-Hodgkin Lymphomas Patients Treated With Rituximab Based Chemotherapy. Dig Liver Dis (2016) 48(11):1394-7. doi: 10.1016/j.dld.2016.08.113

22. Hwang JP, Ferrajoli A, Lok AS. Hepatitis B Reactivation After Chemoimmunotherapy: Screen Before Treatment. Lancet (2021) 397 (10273):510. doi: 10.1016/S0140-6736(21)00210-5

23. Pattullo V. Prevention of Hepatitis B Reactivation in the Setting of Immunosuppression. Clin Mol Hepatol (2016) 22(2):219-37. doi: 10.3350/ cmh.2016.0024

24. Su WP, Wen CC, Hsiung CA, Su IJ, Cheng AL, Chang MC, et al. Long-Term Hepatic Consequences of Chemotherapy-Related HBV Reactivation in Lymphoma Patients. World J Gastroenterol (2005) 11(34):5283-8. doi: 10.3748/wjg.v11.i34.5283

25. Arora A, Anand AC, Kumar A, Singh SP, Aggarwal R, Dhiman RK, et al. Inasl Guidelines on Management of Hepatitis B Virus Infection in Patients Receiving Chemotherapy, Biologicals, Immunosupressants, or Corticosteroids. J Clin Exp Hepatol (2018) 8(4):403-31. doi: 10.1016/j.jceh.2018.06.010

26. Terrault NA, Lok ASF, McMahon BJ, Chang KM, Hwang JP, Jonas MM, et al. Update on Prevention, Diagnosis, and Treatment of Chronic Hepatitis B: Aasld 2018 Hepatitis B Guidance. Clin Liver Dis (Hoboken) (2018) 12 (1):33-4. doi: 10.1002/cld.728

27. Sarin SK, Kumar M, Lau GK, Abbas Z, Chan HL, Chen CJ, et al. Asian-Pacific Clinical Practice Guidelines on the Management of Hepatitis B: A 2015 Update. Hepatol Int (2016) 10(1):1-98. doi: 10.1007/s12072-015-9675-4

28. Perrillo RP, Gish R, Falck-Ytter YT. American Gastroenterological Association Institute Technical Review on Prevention and Treatment of Hepatitis B Virus Reactivation During Immunosuppressive Drug Therapy. Gastroenterology (2015) 148(1):221-44.e3. doi: 10.1053/j.gastro.2014.10.038

29. European Association for the Study of the Liver. Electronic Address Eee, European Association for the Study of the L. Easl 2017 Clinical Practice Guidelines on the Management of Hepatitis B Virus Infection. J Hepatol (2017) 67(2):370-98. doi: 10.1016/j.jhep.2017.03.021

30. Reddy KR, Beavers KL, Hammond SP, Lim JK, Falck-Ytter YT. American Gastroenterological Association I. American Gastroenterological Association Institute Guideline on the Prevention and Treatment of Hepatitis B Virus Reactivation During Immunosuppressive Drug Therapy. Gastroenterology (2015) 148(1):215-9. doi: 10.1053/j.gastro.2014.10.039

31. Yeo W, Johnson PJ. Diagnosis, Prevention and Management of Hepatitis B Virus Reactivation During Anticancer Therapy. Hepatology (2006) 43 (2):209-20. doi: 10.1002/hep.21051

32. Aldhaleei WA, Alnuaimi A, Bhagavathula AS. Covid-19 Induced Hepatitis B Virus Reactivation: A Novel Case From the United Arab Emirates. Cureus (2020) 12(6):e8645. doi: 10.7759/cureus.8645

33. Pley CM, McNaughton AL, Matthews PC, Lourenco J. The Global Impact of the COVID-19 Pandemic on the Prevention, Diagnosis and Treatment of Hepatitis B Virus (HBV) Infection. BMJ Glob Health (2021) 6(1):e004275. doi: 10.1136/bmjgh-2020-004275 
34. Reddy KR. Sars-CoV-2 and the Liver: Considerations in Hepatitis B and Hepatitis C Infections. Clin Liver Dis (Hoboken) (2020) 15(5):191-4. doi: 10.1002/cld.970

35. Loomba R, Liang TJ. Hepatitis B Reactivation Associated With Immune Suppressive and Biological Modifier Therapies: Current Concepts, Management Strategies, and Future Directions. Gastroenterology (2017) 152(6):1297-309. doi: 10.1053/j.gastro.2017.02.009

36. Doo EC, Hoofnagle JH, Rodgers GP. NIH Consensus Development Conference: Management of Hepatitis B. Introduction. Hepatology (2009) 49(5 Suppl):S1-3. doi: 10.1002/hep.22993

37. Yeo W, Chan PK, Zhong S, Ho WM, Steinberg JL, Tam JS, et al. Frequency of Hepatitis B Virus Reactivation in Cancer Patients Undergoing Cytotoxic Chemotherapy: A Prospective Study of 626 Patients With Identification of Risk Factors. J Med Virol (2000) 62(3):299-307. doi: 10.1002/1096-9071 (200011)62:3<299::aid-jmv1>3.0.co;2-0

38. Sagnelli C, Pisaturo M, Calo F, Martini S, Sagnelli E, Coppola N. Reactivation of Hepatitis B Virus Infection in Patients With HemoLymphoproliferative Diseases, and its Prevention. World J Gastroenterol (2019) 25(26):3299-312. doi: 10.3748/wig.v25.i26.3299

39. Yeo W, Zee B, Zhong S, Chan PK, Wong WL, Ho WM, et al. Comprehensive Analysis of Risk Factors Associating With Hepatitis B Virus (HBV) Reactivation in Cancer Patients Undergoing Cytotoxic Chemotherapy. $\mathrm{Br}$ J Cancer (2004) 90(7):1306-11. doi: 10.1038/sj.bjc.6601699

40. Salpini R, Colagrossi L, Bellocchi MC, Surdo M, Becker C, Alteri C, et al. Hepatitis B Surface Antigen Genetic Elements Critical for Immune Escape Correlate With Hepatitis B Virus Reactivation Upon Immunosuppression. Hepatology (2015) 61(3):823-33. doi: 10.1002/hep.27604

41. Shouval D, Shibolet O. Immunosuppression and HBV Reactivation. Semin Liver Dis (2013) 33(2):167-77. doi: 10.1055/s-0033-1345722

42. Borentain P, Colson P, Coso D, Bories E, Charbonnier A, Stoppa AM, et al. Clinical and Virological Factors Associated With Hepatitis B Virus Reactivation in HBsAg-negative and Anti-HBc Antibodies-Positive Patients Undergoing Chemotherapy and/or Autologous Stem Cell Transplantation for Cancer. J Viral Hepat (2010) 17(11):807-15. doi: 10.1111/j.1365-2893.2009.01239.x

43. Kelling M, Sokol L, Dalia S. Hepatitis B Reactivation in the Treatment of Non-Hodgkin Lymphoma. Cancer Control (2018) 25(1):1073274818767879. doi: $10.1177 / 1073274818767879$

44. Smalls DJ, Kiger RE, Norris LB, Bennett CL, Love BL. Hepatitis B Virus Reactivation: Risk Factors and Current Management Strategies. Pharmacotherapy (2019) 39(12):1190-203. doi: 10.1002/phar.2340

45. Ziogas DC, Kostantinou F, Cholongitas E, Anastasopoulou A, Diamantopoulos P, Haanen $\mathrm{J}$, et al. Reconsidering the Management of Patients With Cancer With Viral Hepatitis in the Era of Immunotherapy. J Immunother Cancer (2020) 8(2):e000943. doi: 10.1136/jitc-2020-000943

46. Ozoya OO, Chavez J, Sokol L, Dalia S. Optimizing Antiviral Agents for Hepatitis B Management in Malignant Lymphomas. Ann Transl Med (2017) 5(3):39. doi: 10.21037/atm.2016.12.25

47. Iannitto E, Minardi V, Calvaruso G, Mule A, Ammatuna E, Di Trapani R, et al. Hepatitis B Virus Reactivation and Alemtuzumab Therapy. Eur J Haematol (2005) 74(3):254-8. doi: 10.1111/j.1600-0609.2004.00375.x

48. Merli M, Rattotti S, Gotti M, Arcaini L. Antiviral Therapies for Managing Viral Hepatitis in Lymphoma Patients. Expert Opin Pharmacother (2017) 18 (4):363-76. doi: 10.1080/14656566.2017.1288718

49. Oh MJ, Lee HJ. A Study of Hepatitis B Virus Reactivation Associated With Rituximab Therapy in Real-World Clinical Practice: A Single-Center Experience. Clin Mol Hepatol (2013) 19(1):51-9. doi: 10.3350/cmh.2013.19.1.51

50. Xu X, Shang Q, Chen X, Nie W, Zou Z, Huang A, et al. Reversal of B-cell Hyperactivation and Functional Impairment Is Associated With HBsAg Seroconversion in Chronic Hepatitis B Patients. Cell Mol Immunol (2015) 12 (3):309-16. doi: 10.1038/cmi.2015.25

51. Weiner GJ. Rituximab: Mechanism of Action. Semin Hematol (2010) 47 (2):115-23. doi: 10.1053/j.seminhematol.2010.01.011

52. Mozessohn L, Chan KK, Feld JJ, Hicks LK. Hepatitis B Reactivation in HBsAgnegative/HBcAb-positive Patients Receiving Rituximab for Lymphoma: A MetaAnalysis. J Viral Hepat (2015) 22(10):842-9. doi: 10.1111/jvh.12402

53. Notsumata K, Nomura Y, Tanaka A, Nomura Y, Ueda T, Sanada T, et al. Efficient Prophylactic Management of HBV Reactivation by an Information Technology Encoding System: Results of a 6-Year Prospective Cohort Study. Intern Med (2020) 59(20):2457-64. doi: 10.2169/internalmedicine.4445-20
54. Hara T, Oka K, Iwai N, Inada Y, Tsuji T, Okuda T, et al. Hepatitis B Virus Reactivation 55 Months Following Chemotherapy Including Rituximab and Autologous Peripheral Blood Stem Cell Transplantation for Malignant Lymphoma. Intern Med (2021) 60(3):417-21. doi: 10.2169/ internalmedicine.5678-20

55. Pei SN, Chen CH, Lee CM, Wang MC, Ma MC, Hu TH, et al. Reactivation of Hepatitis B Virus Following Rituximab-Based Regimens: A Serious Complication in Both HBsAg-positive and HBsAg-negative Patients. Ann Hematol (2010) 89(3):255-62. doi: 10.1007/s00277-009-0806-7

56. Mendez-Navarro J, Corey KE, Zheng H, Barlow LL, Jang JY, Lin W, et al. Hepatitis B Screening, Prophylaxis and Re-Activation in the Era of Rituximab-Based Chemotherapy. Liver Int (2011) 31(3):330-9. doi: $10.1111 / j .1478-3231.2010 .02332 . x$

57. Chen XQ, Peng JW, Lin GN, Li M, Xia ZJ. The Effect of Prophylactic Lamivudine on Hepatitis B Virus Reactivation in HBsAg-Positive Patients With Diffuse Large B-cell Lymphoma Undergoing Prolonged Rituximab Therapy. Med Oncol (2012) 29(2):1237-41. doi: 10.1007/s12032-011-9974-0

58. Mitka M. Fda: Increased HBV Reactivation Risk With Ofatumumab or Rituximab. JAMA (2013) 310(16):1664. doi: 10.1001/jama.2013.281115

59. Di Bisceglie AM, Lok AS, Martin P, Terrault N, Perrillo RP, Hoofnagle JH. Recent US Food and Drug Administration Warnings on Hepatitis B Reactivation With Immune-Suppressing and Anticancer Drugs: Just the Tip of the Iceberg? Hepatology (2015) 61(2):703-11. doi: 10.1002/hep.27609

60. Wang B, Mufti G, Agarwal K. Reactivation of Hepatitis B Virus Infection in Patients With Hematologic Disorders. Haematologica (2019) 104(3):435-43. doi: 10.3324/haematol.2018.210252

61. Sagnelli E, Manzillo G, Maio G, Pasquale G, Felaco FM, Filippini P, et al. Serum Levels of Hepatitis B Surface and Core Antigens During Immunosuppressive Treatment of HBsAg-positive Chronic Active Hepatitis. Lancet (1980) 2 (8191):395-7. doi: 10.1016/s0140-6736(80)90442-0

62. Bessone F, Dirchwolf M. Management of Hepatitis B Reactivation in Immunosuppressed Patients: An Update on Current Recommendations. World J Hepatol (2016) 8(8):385-94. doi: 10.4254/wjh.v8.i8.385

63. Cheng AL, Hsiung CA, Su IJ, Chen PJ, Chang MC, Tsao CJ, et al. SteroidFree Chemotherapy Decreases Risk of Hepatitis B Virus (HBV) Reactivation in HBV-carriers With Lymphoma. Hepatology (2003) 37(6):1320-8. doi: 10.1053/jhep.2003.50220

64. Tur-Kaspa R, Burk RD, Shaul Y, Shafritz DA. Hepatitis B Virus DNA Contains a Glucocorticoid-Responsive Element. Proc Natl Acad Sci USA (1986) 83(6):1627-31. doi: 10.1073/pnas.83.6.1627

65. He Q, Song X, Huang Y, Huang W, Ye B, Luo H, et al. Dexamethasone Stimulates Hepatitis B Virus (Hbv) Replication Through Autophagy. Med Sci Monit (2018) 24:4617-24. doi: 10.12659/MSM.906250

66. Paul S, Saxena A, Terrin N, Viveiros K, Balk EM, Wong JB. Hepatitis B Virus Reactivation and Prophylaxis During Solid Tumor Chemotherapy: A Systematic Review and Meta-Analysis. Ann Intern Med (2016) 164(1):3040. doi: 10.7326/M15-1121

67. Chen YF, Chong CL, Wu YC, Wang YL, Tsai KN, Kuo TM, et al. Doxorubicin Activates Hepatitis B Virus Replication by Elevation of p21 (Waf1/Cip1) and C/EBPalpha Expression. PloS One (2015) 10(6):e0131743. doi: 10.1371/journal.pone. 0131743

68. Lake AC. Hepatitis B Reactivation in a Long-Term Nonprogressor Due to Nivolumab Therapy. AIDS (2017) 31(15):2115-8. doi: 10.1097/QAD.0000000000001599

69. Pandey A, Ezemenari S, Liaukovich M, Richard I, Boris A. A Rare Case of Pembrolizumab-Induced Reactivation of Hepatitis B. Case Rep Oncol Med (2018) 2018:5985131. doi: 10.1155/2018/5985131

70. Kundumadam S, Mohamad B, Muthusamy A, Kathi PR, Ehrinpreis MN. Pembrolizumab-Induced Immune-Mediated Hepatitis and Concurrent Hepatitis B Reactivation in a Patient With Non-Small Cell Lung Cancer. Cureus (2020) 12(11):e11522. doi: 10.7759/cureus.11522

71. Koksal AS, Toka B, Eminler AT, Hacibekiroglu I, Uslan MI, Parlak E. HBVRelated Acute Hepatitis Due to Immune Checkpoint Inhibitors in a Patient With Malignant Melanoma. Ann Oncol (2017) 28(12):3103-4. doi: 10.1093/ annonc/mdx502

72. Zhang X, Zhou Y, Chen C, Fang W, Cai X, Zhang X, et al. Hepatitis B Virus Reactivation in Cancer Patients With Positive Hepatitis B Surface Antigen Undergoing PD-1 Inhibition. J Immunother Cancer (2019) 7(1):322. doi: $10.1186 / s 40425-019-0808-5$ 
73. Hwang JP, Feld JJ, Hammond SP, Wang SH, Alston-Johnson DE, Cryer DR, et al. Hepatitis B Virus Screening and Management for Patients With Cancer Prior to Therapy: Asco Provisional Clinical Opinion Update. J Clin Oncol (2020) 38(31):3698-715. doi: 10.1200/JCO.20.01757

74. 2020 NCCNB-cl. Available at: https://www.nccn.org/professionals/ physician_gls/pdf/b-cell.pdf (Accessed January 3, 2021).

75. Liang R. How I Treat and Monitor Viral Hepatitis B Infection in Patients Receiving Intensive Immunosuppressive Therapies or Undergoing Hematopoietic Stem Cell Transplantation. Blood (2009) 113(14):3147-53. doi: 10.1182/blood-2008-10-163493

76. Lok AS, McMahon BJ. Chronic Hepatitis B: Update 2009. Hepatology (2009) 50(3):661-2. doi: 10.1002/hep.23190

77. Lau GK, Yiu HH, Fong DY, Cheng HC, Au WY, Lai LS, et al. Early is Superior to Deferred Preemptive Lamivudine Therapy for Hepatitis B Patients Undergoing Chemotherapy. Gastroenterology (2003) 125(6):17429. doi: $10.1053 /$ j.gastro.2003.09.026

78. Hsu C, Hsiung CA, Su IJ, Hwang WS, Wang MC, Lin SF, et al. A Revisit of Prophylactic Lamivudine for Chemotherapy-Associated Hepatitis B Reactivation in non-Hodgkin's Lymphoma: A Randomized Trial. Hepatology (2008) 47(3):844-53. doi: 10.1002/hep.22106

79. Ziakas PD, Karsaliakos P, Mylonakis E. Effect of Prophylactic Lamivudine for Chemotherapy-Associated Hepatitis B Reactivation in Lymphoma: A Meta-Analysis of Published Clinical Trials and a Decision Tree Addressing Prolonged Prophylaxis and Maintenance. Haematologica (2009) 94(7):9981005. doi: 10.3324/haematol.2009.005819

80. Yu S, Luo H, Pan M, Luis AP, Xiong Z, Shuai P, et al. Comparison of Entecavir and Lamivudine in Preventing HBV Reactivation in Lymphoma Patients Undergoing Chemotherapy: A Meta-Analysis. Int J Clin Pharm (2016) 38(5):1035-43. doi: 10.1007/s11096-016-0358-6

81. Loglio A, Vigano M, Grossi G, Labanca S, Goldaniga M, Pompa A, et al. Lamivudine Prophylaxis Prevents Hepatitis B Virus Reactivation in anti$\mathrm{HBc}$ Positive Patients Under Rituximab for Non-Hodgkin Lymphoma. Dig Liver Dis (2019) 51(3):419-24. doi: 10.1016/j.dld.2018.08.024

82. Law JK, Ali JA, Harrigan PR, Sherlock CH, Savage KJ, Yoshida EM. Fatal Postlymphoma Chemotherapy Hepatitis B Reactivation Secondary to the Emergence of a YMDD Mutant Strain With Lamivudine Resistance in a Noncirrhotic Patient. Am J Hematol (2006) 81(12):969-72. doi: 10.1002/ajh.20737

83. Loomba R, Rowley A, Wesley R, Liang TJ, Hoofnagle JH, Pucino F, et al. Systematic Review: The Effect of Preventive Lamivudine on Hepatitis B Reactivation During Chemotherapy. Ann Intern Med (2008) 148(7):519-28. doi: 10.7326/0003-4819-148-7-200804010-00008

84. Zhang MY, Zhu GQ, Shi KQ, Zheng JN, Cheng Z, Zou ZL, et al. Systematic Review With Network Meta-Analysis: Comparative Efficacy of Oral Nucleos(T) Ide Analogues for the Prevention of Chemotherapy-Induced Hepatitis B Virus Reactivation. Oncotarget (2016) 7(21):30642-58. doi: 10.18632/oncotarget.8907

85. Yang C, Qin B, Yuan Z, Chen L, Zhou HY. Meta-Analysis of Prophylactic Entecavir or Lamivudine Against Hepatitis B Virus Reactivation. Ann Hepatol (2016) 15(4):501-11. doi: 10.5604/16652681.1202910

86. Hwang JP, Artz AS, Somerfield MR. Hepatitis B Virus Screening for Patients With Cancer Before Therapy: American Society of Clinical Oncology Provisional Clinical Opinion Update. J Oncol Pract (2015) 11(4):e487-9. doi: 10.1200/JOP.2015.004846

87. Tseng CM, Chen TB, Hsu YC, Chang CY, Lin JT, Mo LR. Comparative Effectiveness of Nucleos(T)Ide Analogues in Chronic Hepatitis B Patients Undergoing Cytotoxic Chemotherapy. Asia Pac J Clin Oncol (2016) 12 (4):421-9. doi: 10.1111/ajco.12520

88. Wani MA, Sodhi JS, Yatoo GN, Shah A, Geelani S, Zargar SA, et al. Clinical Profile and Efficacy of Antivirals in Hepatitis B Virus Reactivation, in Patients With Cancer Receiving Chemotherapy. J Clin Exp Hepatol (2020) 10(6):590-8. doi: 10.1016/j.jceh.2020.06.008

89. Li HR, Huang JJ, Guo HQ, Zhang X, Xie Y, Zhu HL, et al. Comparison of Entecavir and Lamivudine in Preventing Hepatitis B Reactivation in Lymphoma Patients During Chemotherapy. J Viral Hepat (2011) 18 (12):877-83. doi: 10.1111/j.1365-2893.2010.01386.x

90. Huang $\mathrm{H}$, Li X, Zhu J, Ye S, Zhang H, Wang W, et al. Entecavir vs Lamivudine for Prevention of Hepatitis B Virus Reactivation Among
Patients With Untreated Diffuse Large B-cell Lymphoma Receiving RCHOP Chemotherapy: A Randomized Clinical Trial. JAMA (2014) 312 (23):2521-30. doi: 10.1001/jama.2014.15704

91. Koskinas JS, Deutsch M, Adamidi S, Skondra M, Tampaki M, Alexopoulou A, et al. The Role of Tenofovir in Preventing and Treating Hepatitis B Virus (HBV) Reactivation in Immunosuppressed Patients. A Real Life Experience From a Tertiary Center. Eur J Intern Med (2014) 25(8):768-71. doi: 10.1016/ j.ejim.2014.06.028

92. Zheng JN, Zou TT, Zou H, Zhu GQ, Ruan LY, Cheng Z, et al. Comparative Efficacy of Oral Nucleotide Analogues for the Prophylaxis of Hepatitis B Virus Recurrence After Liver Transplantation: A Network Meta-Analysis. Expert Rev Anti Infect Ther (2016) 14(10):979-87. doi: 10.1080/ 14787210.2016 .1220831

93. Ceccarelli L, Salpini R, Sarmati L, Svicher V, Bertoli A, Sordillo P, et al. Late Hepatitis B Virus Reactivation After Lamivudine Prophylaxis Interruption in an anti-HBs-positive and anti-HBc-negative Patient Treated With Rituximab-Containing Therapy. J Infect (2012) 65(2):180-3. doi: 10.1016/ j.jinf.2011.11.021

94. Muraishi J, Shibata M, Honma Y, Hiura M, Abe S, Harada M. Reactivation of Occult Hepatitis B Virus Infection 27 Months After the End of Chemotherapy Including Rituximab for Malignant Lymphoma. Intern Med (2017) 56(15):1967-71. doi: 10.2169/internalmedicine.56.8233

95. Cerva C, Colagrossi L, Maffongelli G, Salpini R, Di Carlo D, Malagnino V, et al. Persistent Risk of HBV Reactivation Despite Extensive Lamivudine Prophylaxis in Haematopoietic Stem Cell Transplant Recipients Who Are anti-HBc-positive or HBV-negative Recipients With an anti-HBc-positive Donor. Clin Microbiol Infect (2016) 22(11):946.e1-e8. doi: 10.1016/ j.cmi.2016.07.021

96. Liu WP, Wang XP, Zheng W, Ping LY, Zhang C, Wang GQ, et al. Hepatitis B Virus Reactivation After Withdrawal of Prophylactic Antiviral Therapy in Patients With Diffuse Large B Cell Lymphoma. Leuk Lymphoma (2016) 57 (6):1355-62. doi: 10.3109/10428194.2015.1116121

97. Nakaya A, Fujita S, Satake A, Nakanishi T, Azuma Y, Tsubokura Y, et al. Delayed HBV Reactivation in Rituximab-Containing Chemotherapy: How Long Should We Continue Anti-Virus Prophylaxis or Monitoring HBVDNA? Leuk Res (2016) 50:46-9. doi: 10.1016/j.leukres.2016.09.014

98. Hwang JP, Fisch MJ, Zhang H, Kallen MA, Routbort MJ, Lal LS, et al. Low Rates of Hepatitis B Virus Screening at the Onset of Chemotherapy. J Oncol Pract (2012) 8(4):e32-9. doi: 10.1200/JOP.2011.000450

99. Hwang JP, Fisch MJ, Lok AS, Zhang H, Vierling JM, Suarez-Almazor ME. Trends in Hepatitis B Virus Screening at the Onset of Chemotherapy in a Large US Cancer Center. BMC Cancer (2013) 13:534. doi: 10.1186/14712407-13-534

100. Visram A, Chan KK, McGee P, Boro J, Hicks LK, Feld JJ. Poor Recognition of Risk Factors for Hepatitis B by Physicians Prescribing Immunosuppressive Therapy: A Call for Universal Rather Than Risk-Based Screening. PLoS One (2015) 10(4):e0120749. doi: 10.1371/journal.pone.0120749

101. Hwang JP, Lok AS, Fisch MJ, Cantor SB, Barbo A, Lin HY, et al. Models to Predict Hepatitis B Virus Infection Among Patients With Cancer Undergoing Systemic Anticancer Therapy: A Prospective Cohort Study. J Clin Oncol (2018) 36(10):959-67. doi: 10.1200/JCO.2017.75.6387

102. Hashino S, Nozawa A, Izumiyama K, Yonezumi M, Chiba K, Kondo T, et al. Lamivudine Treatment for Reverse Seroconversion of Hepatitis B 4 Years After Allogeneic Bone Marrow Transplantation. Bone Marrow Transplant (2002) 29(4):361-3. doi: 10.1038/sj.bmt.1703387

Conflict of Interest: The authors declare that the research was conducted in the absence of any commercial or financial relationships that could be construed as a potential conflict of interest.

Copyright $\odot 2021$ Cao, Wang, Li, Huang, Lu and Lu. This is an open-access article distributed under the terms of the Creative Commons Attribution License (CC BY). The use, distribution or reproduction in other forums is permitted, provided the original author(s) and the copyright owner(s) are credited and that the original publication in this journal is cited, in accordance with accepted academic practice. No use, distribution or reproduction is permitted which does not comply with these terms. 